\title{
BENGKEL MOTOR CUSTOM
}

\author{
Felix Halim ${ }^{1)}$, Stephanus Huwae ${ }^{2)}$
}

1)Program Studi S1 Arsitektur, Fakultas Teknik, Universitas Tarumanagara, felixhalim97@gmail.com

2) Program Studi S1 Arsitektur, Fakultas Teknik, Universitas Tarumanagara, ituuuuut@yahoo.com

\begin{abstract}
Abstrak
Motor Custom adalah motor yang dibuat/ diubah sesuai dengan kebutuhan pembeli, pengguna, atau sepesifikasi individu tertentu. Perubahan fungsi motor yang semula merupakan alat transportasi dari satu titik ke titik lain, sekarang bertambah menjadi suatu gaya hidup/lifestyle. Fenomena ini muncul sebagai imbas perubahan pola kebutuhan masyarakat dari basic needs menjadi leisure needs. Generasi Milenial basic needs sudah terpenuhi, maka generasi Milenial menurut Teori Maslow berada di tingkat selanjutnya yaitu di tahap psychological needs. Ekonomi kreatif menjadi tulang punggung perekonomian Indonesia. Dukungan pemerintah akan industri-industri kreatif melalui Bekraf (Badan Ekonomi Kreatif) merupakan tanda positif untuk membuat wadah pembuatan motor custom di Indonesia. Untuk memulai usaha bengkel mereka membutuhkan network, tools, dan wadah/ tempat. Bengkel Motor Custom dapat membantu start-up untuk membuka Bengkel Motor Custom dengan cara memberikan kebutuhan mereka. Sharing tools dapat meringankan dalam memulai usaha bengkel mereka, dikarenakan usaha yang mereka jalankan memiliki tools yang digunakan secara bersama-sama dengan start-up lainnya. Bengkel Motor Custom berada di daerah Kemang, dimana fenomena motor riding bersama sering ditemukan ketika Sunday Morning Ride. Fenomena tersebut direkam dan dituangkan ke dalam desain menggunakan metode Pattern Language, yang dapat membuat keterkaitan antara program dengan lingkungan menjadi kuat. Dari fenomena dan teori yang telah dikaji dapat dilihat bahwa peluang Bengkel Motor Custom untuk Milenial cukup sesuai. Bengkel Motor Custom dapat memberikan pengalaman merakit dan memodifikasi motornya juga dapat dilakukan sendiri dengan memakai tools yang direntalkan. Tujuan dari hadirnya Bengkel Motor Custom untuk memajukan industri kreatif Indonesia, mampu memunculkan produk yang inovatif, serta dapat mengedukasi masyarakat luas tentang otomotif dan meningkatkan daya tarik akan produk lokal.
\end{abstract}

Kata kunci: Bengkel; Custom; Kemang; Kreatif; Motor

\begin{abstract}
A motor custom is a motorcycle that is made/modified based on buyer needs, user, or a particular individual's specification. Motorcycle originally functioned as a means of transportation from one point to another, yet it has now evolved into a new kind of lifestyle. This phenomenon emerged as an impact of changes in the society's pattern of needs, going from basic needs into leisure needs. The milenial generation's basic needs were mostly fulfilled; therefore, according to The Maslow Theory, the generation is now in the next stage which is psychological needs. Creative economy has become the backbone of Indonesia's economy. The government's support towards creative industries through Bekraf is a positive sign to provide a space for motorcycle enthusiasts to produce motor custom les in Indonesia. To start a workshop business, they need network, tools, and a place. Economic incubator can help start-ups to open Motor Custom Workshop by providing their need. Sharing tools offer start-ups with equipment that they can use together, helping start-ups to start their business without having to spend a lot of capital buying their own equipment. Motor Custom Workshop is located in Kemang, where motorcycle communities are often found on the streets, on their Sunmori. This phenomenon is recorded and incorporated into design by using Pattern Language method, which is able to strengthen the link between program and the surroundings. From the phenomena and theories reviewed, it can be concluded that Motor Custom Workshop for Milenials is a potential business venture. Motor Custom Workshop offers opportunity for motorcycle enthusiasts hoping to delve in this business to gain experience in assembling and modifying motorcycles with available rental tools. Motor Custom Workshop is expected to promote Indonesia's creative industry, bring out innovative products, educate the public about automotif, and increase the appeal of local product.
\end{abstract}

Key word: Creative; Custom; Kemang; Motor; Workshop 


\section{PENDAHULUAN}

Milenial adalah nama lain generasi $Y$, yakni generasi yang lahir antara tahun 1981-1994. Populasi generasi Milenial tengah berada di usia produktif dan memiliki jumlah terbesar. Tingkat pendidikan generasi Milenial yang lebih baik dari generasi sebelumnya. Sifat Milenial yang konsumtif, experience oriented, praktis, sharing, kreatif. Populasi Milenial di kelas berpendapatan menengah kian menanjak dan sebagaian besar kebutuhan dasar telah terpenuhi, sehingga mereka memilih mengeluarkan pendapatan yang bersifat sekunder. Fenomena ini muncul sebagai imbas perubahan pola kebutuhan masyarakat dari kebutuhan dasar (basic needs) menjadi kebutuhan sekunder (leisure needs).

Perubahan fungsi motor yang semula merupakan alat transportasi dari satu titik ke titik lain, sekarang bertambah menjadi suatu gaya hidup/lifestyle dengan tren Motorn Custom. Motor Custom adalah motor yang dibuat/diubah sesuai dengan kebutuhan pembeli, pengguna, atau sepesifikasi individu tertentu. Fenomena tersebut juga merupakan akibat dari pola hidup yang berubah. Teori Maslow menyatakan bahwa kebutuhan digambarkan sebagai sebuah hierarki atau tangga yang menggambarkan tingkat kebutuhan. Generasi Milenial basic needs sudah terpenuhi, maka generasi Milenial berada di tingkat selanjutnya yaitu di tahap psychological needs. Psychological needs adalah kebutuhan yang diusahakan individu untuk memenuhi dorongan yang sesuai dengan keinginannya sehingga timbulnya kepuasan jiwa.

Indonesia menjadi salah satu negara di dunia yang memiliki kinerja ekonomi paling hebat. Tahun 2015 lalu, kita mencatatkan pertumbuhan Produk Domestik Bruto (PDB) 4,79\%, lebih tinggi daripada pertumbuhan ekonomi global yang diperkirakan hanya mencapai $2,4 \%$. Iklim yang positif ini tentunya menjadi momen yang tepat bagi pemerintah untuk mengokohkan fondasi perekonomian, terutama pada sektor riil, salah satu sektor riil yang sangat layak menjadi prioritas adalah ekonomi kreatif. Ekonomi kreatif kelak menjadi tulang punggung perekonomian Indonesia. Kreativitas dan skill Milenial yang didapat dari internet karena percepatan ilmu pengetahuan yang mudah diakses melalui internet merupakan modal bagi kaum Milenial. Dukungan pemerintah akan industri-industri kreatif melalui Bekraf merupakan tanda positif bagi peluang untuk membuat wadah pembuatan motor custom di Indonesia.

Untuk memulai usaha bengkel mereka membutuhkan network, tools, dan wadah/ tempat. Ekonomi Inkubator dapat membantu mereka (startup) untuk membuka bengkel motor custom dengan cara memberikan network, mentor, sharing tools. Sharing tools dapat meringankan startup dalam menjalankan usaha bengkel mereka, dikarenakan usaha yang mereka jalankan memiliki tools yang digunakan secara bersama-sama dengan startup-startup lainnya. Bagi Milenial yang ingin merasakan experience merakit dan memodifikasi motornya juga dapat dilakukan sendiri dengan memakai tools yang direntalkan. Tujuan dari membuat Bengkel Motor Custom untuk memajukan Industri Kreatif Indonesia, mampu memunculkan produk yang inovatif, serta dapat mengedukasi masyarakat luas tentang otomotif (motor custom), dan meningkatkan daya tarik akan produk lokal.

\section{KAJIAN LITERATUR}

Milenial

Milenial adalah nama lain generasi Y, yakni generasi yang lahir antara tahun 1981-1994.

Populasi generasi Milenial tengah berada di usia produktif dan memiliki jumlah terbesar. Tingkat pendidikan generasi Milenial yang lebih baik dari generasi sebelumnya. Generasi Milenial memiliki signifikansi yang besar untuk membawa perubahan pada dunia ${ }^{1}$.

\footnotetext{
${ }^{1}$ https://www.republika.co.id/berita/jurnalisme-warga/wacana/17/05/15/opziw5396-generasi-Milenial-umkm-dan-media-pemasarandigital
} 


\section{What Makes Your Generation Unique?}

1. Technology use $(24 \%)$
2. Music/Pop culture $(11 \%)$
3. Liberal/tolerant $(7 \%)$
4. Smarter $(6 \%)$
5. Clothes $(5 \%)$

\section{Gen X} Technology use (12\%) Work ethic (11\%) Conservative/Trad'I (7\%) Smarter $16 \%)$ Respectful (5\%)

\section{Boomer}

Work ethic (17\%)

Respectful (14\%)

Values/Morals (8\%)

"Baby Boomers" (6\%)

Smarter (5\%)
Silent

WW II, Depression (14\%)

Smarter (13\%)

Honest (128)

Work ethic $(10 \%)$

Values/Morals (10:)

Note: Based on respondents who said their generation was unique/distinct. Items represent individual, open. ended responses. Top five responses are shown for each age group. Sample sizes for sub-groups are as follows: Millennials, $n=527$; Gen $X, n=173 ;$ Boomers, $n=283$; Silent, $n=205$.

Gambar 1. Generation uniques, Sumber: kompasiana.com/

Generasi Milenial juga generasi pertama dari penduduk asli digital, dan ketertarikan mereka terhadap teknologi membantu membentuk cara mereka berbelanja. Mereka terbiasa dengan akses instan untuk perbandingan harga, informasi produk dan ulasan sejawat ${ }^{2}$. Akhirnya, mereka didedikasikan untuk kesehatan, mencurahkan waktu dan uang untuk berolahraga dan makan dengan benar. Gaya hidup aktif mereka memengaruhi tren dalam segala hal mulai dari makanan dan minuman hingga mode.

\section{Perilaku}

Menurut Robert Y. Kwick (1972) ,Perilaku adalah tindakan atau perbuatan suatu organisme yang dapat diamati dan dipelajari ${ }^{3}$. Menurut Skinner, Perilaku adalah :respon atau reaksi seseorang terhadap stimulus atau rangsangan dari luar. Teori ini disebut teori "S-O-R" (StimulusOrganisme- Respon) $)^{4}$. Menurut Notoatmodjo (2003) , Perilaku manusia adalah semua kegiatan atau aktivitas manusia, baik yang diamati langsung, maupun yang tidak dapat diamati oleh pihak luar ${ }^{5}$. Perilaku manusia adalah suatu perbuatan atau tindakan baik nyata maupun tidak nyata yang merupakan respon terhadap stimulus/ rangsangan dari luar dan dapat diamati dan dipelajari.

\section{Tipe}

Menurut Rafael Moneo (1978), tipe adalah konsep yang mendeskripsikan suatu grup objek dengan karakter struktur formal yang sama ${ }^{6}$. Menurut Tjahjono (1999), kata tipe dipakai dalam beberapa keadaan yang menunjukan, antara lain sifat umum suatu bentuk, kategori, jenis, aturan, contoh, dan model ${ }^{7}$. Tipe merupakan pendeskripsian suatu grup objek. Seperti bentuk, kategori, aturan, contoh, dan model dengan karakter struktur formal yang sama.

\section{Kesejamanan}

Kesejamanan, ke-se-jaman-an, yang memiliki karta dasar yaitu jaman/ zaman. Za.man adalah angka waktu yang panjang atau pendek yang menandai sesuatu; masa ${ }^{8}$.

\footnotetext{
${ }^{2}$ https://news.detik.com/kolom/d-3981811/generasi-milenial-dan-era-industri-40

${ }_{3}^{3}$ Kwick, Robert. 1974. Notoatmodjo, Soekidjo. 2003, Pendidikan Dan Perilaku Kesehatan, Rineka Cipta, Jakarta.

${ }^{4}$ B.F. Skinner. 1938.The Behavior of Organisms: An Experimental Analysis.Cambridge, Massachusetts: B.F. Skinner Foundation..

${ }^{5}$ Notoatmodjo, Soekidjo. 2003. Pendidikan Dan Perilaku Kesehatan. Rineka Cipta. Jakarta.

${ }^{6}$ Moneo, Rafael, 1978, On Typology.

${ }^{7}$ Gunawan Tjahjono. 1999. Metode Perancangan Suatu Pengantar Untuk Arsitek dan Perancang.

${ }^{8}$ https://kbbi.kemdikbud.go.id/entri/zaman
} 


\section{Maslow's Hierarchy of Needs}

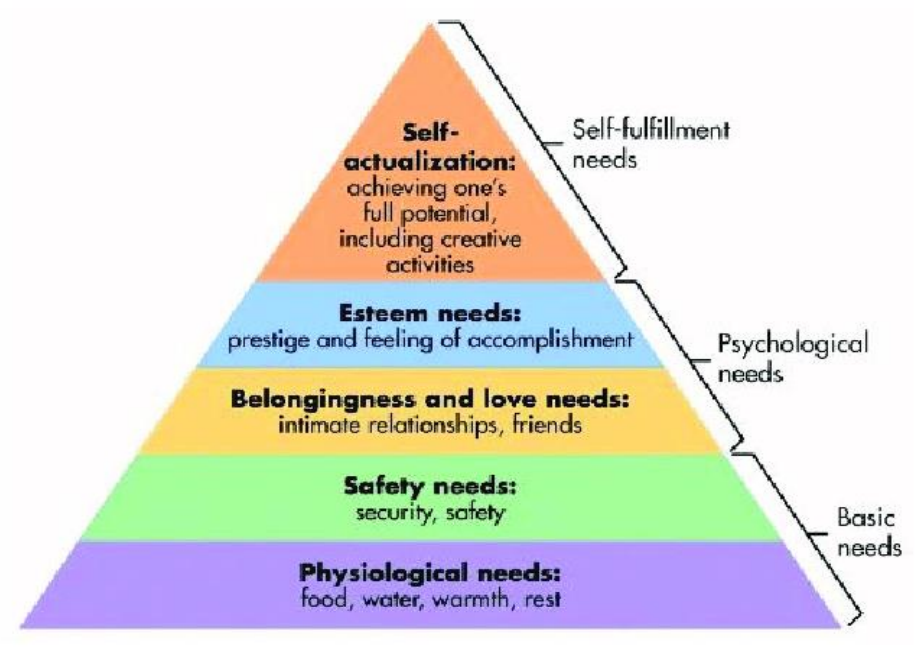

Gambar 2. Diagram Maslow,

Sumber: researchgate.net

Maslow's Hierarchy of Needs terdapat 5 tingkatan kebutuhan didalam diri seseorang, kita akan memulai menjabarkannya dari tingkatan yang paling bawah/ mendasar ${ }^{9}$. 1. Physiological Needs (Kebutuhan Fisiologis), merupakan kebutuhan paling mendasar yang harus dipenuhi oleh seorang manusia agar dapat bertahan hidup, dan kebutuhan ini tentu sangatlah penting serta tidak bisa ditawar lagi. Beberapa contoh kebutuhan fisiologis manusia antara lain seperti makan, minum, tidur, rumah, bernafas, dsb. 2. Safety Needs (Kebutuhan akan rasa nyaman/aman), yang kedua ini biasanya muncul keinginan didalam diri seorang manusia ketika kebutuhan dasar (fisiologis) nya telah terpenuhi. Manusia membutuhkan rasa aman ketika menjalani hidupnya dapat berupa perlindungan keamanan dalam pekerjaan, jaminan kesehatan diri/keluarga, jaminan keberlangsungan pekerjaannya, jaminan keamanan dihari tua saat tidak bekerja/produktif. 3. Belonging/Social Needs (Kebutuhan Sosial), Apabila kedua kebutuhan dasar tadi telah terpenuhi secara minimal/cukup, manusia cenderung menginginkan untuk menjalin hubungan secara sosial, manusia membutuhkan afiliasi dan berinteraksi dengan sesama/lawan jenisnya manusia.

4. Esteem Needs ( Kebutuhan akan penghargaan), ketika manusia sudah berinteraksi secara intens dengan lingkungan sosial nya, makan muncul keinginan dari dalam diri sendiri untuk ingin merasa dihormati, diapresiasi, serta diakui akan keahlian maupun kemampuannya dalam melakukukan suatu hal. Intinya manusia membutuhkan penghargaan diri atas segala sesuatu. 5. Self Actualization Needs (Kebutuhan aktualisasi diri), aktualisasi diri merupakan tingkatan tertinggi didalam diri manusia menurut Maslow's Hierarchy of Needs. Pada tingkatan ini, sesungguhya mempunyai hubungan yang sagat erat denga proses pengembangan diri maupun potensi yang dimiliki oleh seseorang. Kebutuhan untuk menunjukan potensi, kelebihan, keahlian, skill maupun ilmu yang dimiliki seseorang. Didalam self actualization, manusia cenderung mengalami peningkatan didalam dirinya. Apabila didalam tingkatan ini manusia mempunanyai aktualisasi diri yang sangat kuat, maka manusia tersebut akan sangat menyukai hal hal yang sesuai dengan passion maupun potensi yang ada dalam dirinya, karena merasa sangat membutuhkannya untuk terus meningkatnkannya.

\section{Pengertian Bengkel}

Bengkel atau lokakarya adalah sebuah bangunan yang menyediakan ruang dan peralatan untuk melakukan konstruksi atau manufaktur atau memperbaiki benda, sedangkan perbengkelan adalah pengetahuan dan keterampilan tentang peralatan dan metode

\footnotetext{
${ }^{9}$ https://www.kompasiana.com/anantayoga/552a7b976ea8340c0a552d02/maslow-s-hierarchy-ofneeds
} 
untuk membuat, membentuk, mengubah bentuk, merakit, ataupun memperbaiki suatu benda menjadi bentuk yang baru atau kondisi yang lebih baik secara manfaat maupun estetika ${ }^{10}$.

Menurut KBBI Bengkel /béngkél/ tempat memperbaiki mobil, sepeda, dan sebagainya; pabrik kecil; tempat tukang bekerja; tempat melakukan suatu kegiatan dengan arah dan tujuan yang pasti ${ }^{11}$. Menurut Soedarma (2006) Bengkel otomotif adalah tempat dimana kendaraan diperbaiki oleh teknisi atau tenaga mekanik ${ }^{12}$. Menurut lqbal (2004) pengklasifikasian bengkel motor secara umum dapat dibagi diantaranya sebagai berikut bengkel yang berfungsi untuk memperbaiki dan merawat kendaraan bermotor agar tetap memenuhi persyaratan teknis dan layak jalan, yang selanjutnya dalam buku panduan ini disebut dengan bengkel.

Bengkel Modifikasi adalah proses modifikasi yang dilakukan dengan sistem kerja yang standar, merubah spesifikasi komponen ataupun dengan cara memberi komponen tambahan. Sepeda motor bisa tampak lebih cantik, lebih manis, ini disebabkan kendaraan itu sudah dimodifikasi sehingga tampil beda dari biasanya.

\section{Sepeda Motor Modifikasi}

Menurut Setiawan (2007), pengertian modifikasi dapat diartikan sebagai upaya melakukan perubahan dengan penyesuaian-penyesuaian baik dalam segi fisik material (fasilitas dan perlengkapan) maupun dalam tujuan dan cara (metoda, gaya, pendekatan, aturan serta penilaian). Dari pernyataan diatas mengenai pengertian modifikasi, modifikasi merupakan suatu usaha perubahan yang dilakukan berupa penyesuaian-penyesuaian baik dalam bentuk fasilitas dan perlengkapan atau dalam metoda, gaya, pendekatan, aturan serta penilaian.

Perkembangan industri untuk produk sepeda motor dewasa ini bisa dikatakan cukup drastis, dilihat dari berbagai model dari merk-merk terkenal, tapi meskipun demikian banyak pecinta kendaraan beroda dua ini atau yang lasim disebut bikers masih belum puas dengan model yang ada, maka itu mereka membuat model-model yang sesuai dengan kreasi mereka sendiri ataupun dibantu oleh para modifikator. Dilakukannya modifikasi motor oleh penggemarnya didasari oleh beberapa hal diantaranya untuk mengikuti sebuah kontes modifikasi ataupun hanya sebagai hobi. Menurut para bikers, modifikasi sepeda motor selain berguna untuk menyalurkan kreatifitas juga merupakan ajang penunjukan jati diri si-pengendara kuda besi tersebut. Sejalan dengan perkembangan jaman, modifikasi motor semakin maraknya dilakukan. Hal ini ditunjukkan dengan adanya berbagai kontes modifikasi motor, dan banyak pula perkumpulan-perkumpulan bikers. Salah satu event terbesar kontes modifikasi motor yang ada di Indonesia adalah "Jogja Kustomfest". Event ini banyak menghadirkan modifikasi-modifikasi motor terbaru dari seluruh Indonesia. "Jogja Kustomfest" terinspirasi dari kontes modifikasi motor yang berada di Yokohama Jepang ${ }^{13}$. Menurut Soedarma (2006) jenis aliran modifikasi pada sepeda motor dapat dijabarkan sebagai berikut ${ }^{14}$ :

1. Modifikasi Cafe Racer Yang menjadi ciri khas dari motor-motor ala Cafe Racer ini adalah mesin dengan tenaga besar, suaranya yang bising, memiliki body yang ringan serta hanya memiliki 1 jok (single seater). Motor Cafe Racer ini juga lebih mengutamakan kecepatan dan kestabilan dibandingkan kenyamanan berkendara. Biasanya modifikasi akan menyentuh di bagian mesin yang akan diganti dengan kapasitas dan tenaga yang lebih besar, knalpot yang lebih sangar dan kaki-kaki yang lebih kuat.

2. Modifikasi Bobbers dan Choppers Keduanya berhubungan erat, prinsipnya, Bob dan Chop sama sama melakoni langkah memotong motong. Bedanya, bobber yang hadir lebih dahulu dan tak se extrim chooper. Aliran ini tetap membiarkan sasis standar tapi memotong spatbor dan piranti yang dianggap perlu. Untuk aksentuasi, bobberis menerapkan pakem memilih roda depan dan belakang gendut. Rem teromol dan kick-starter sesuai masa kelahirannya.

\footnotetext{
${ }^{10} \mathrm{https} / / /$ bjmmotor.business.site/

${ }^{11}$ https://kbbi.web.id/bengkel

${ }_{12}^{12}$ Soedarmo, H. 2008. Panduan Praktis Merawat dan Memperbaiki Sepeda Motor. Jakarta : Gramedia.

${ }_{13}^{13}$ Majalah Otomotif: Dapurpacu, 2013

${ }^{14}$ Soedarmo, H. 2008. Panduan Praktis Merawat dan Memperbaiki Sepeda Motor. Jakarta : Gramedia.
} 
Bobberies fanatik, walau punya motor baru, tetap mempertahankan aroma ol skool ini. CHOPPERS lahir dari kebutuhan dan efisiensi dana.

3. Modifikasi Scrambler Dalam dunia modifiasi, scramblers ditandai dengan penguatan kaki kaki, groud clearance yang ditinggikan, ban motorcross dan knalpot melingkar di tengah mesin agar tidak terganggu saat melahap medan ekstrem. Uniknya, aliran ini menghasilkan keindahan tersendiri. Banyak modifikator memilih scrambler dengan karakter bersih dan kinclong.

4. Modifikasi Jap's Style Ciri khas Jap's Style adalah kreativitas nakal bergaya old skool di setang telanjang, lampu bulat, jok bertingkat dengan pelapis berbahan glossy dan detail manik imut. Kadang mereka cuek menyasar beket penangga mesin atau total memanjangkan rangka. Akibatnya ground clearance motor juga makin turun.

\section{Industri Kreatif}

Menurut IKM (Industri Kecil dan Menengah), Industri kreatif merupakan kegiatan usaha yang fokus pada kreasi dan inovasi. Industri kreatif masih potensial untuk digarap, dan Indonesia kaya akan budaya serta tradisi yang bisa menjadi sumber kreativitas ${ }^{15}$.

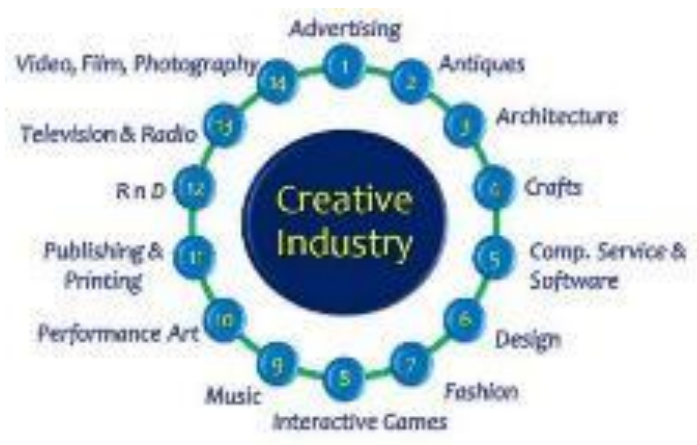

Gambar 3. Diagram Industri Kreatif, Sumber:https://hilfans.staff.telkomuniversity.ac.id/potensi-industri-kreatif/

Indonesia menjadi salah satu negara di dunia yang memiliki kinerja ekonomi paling hebat. Tahun 2015 lalu, kita mencatatkan pertumbuhan Produk Domestik Bruto (PDB) 4,79\%, lebih tinggi daripada pertumbuhan ekonomi global yang diperkirakan hanya mencapai $2,4 \%$. Iklim yang positif ini tentunya menjadi momen yang tepat bagi pemerintah untuk mengokohkan fondasi perekonomian, terutama pada sektor riil.

Salah satu sektor riil yang sangat layak menjadi prioritas adalah ekonomi kreatif. Presiden Joko Widodo optimistis bahwa ekonomi kreatif kelak menjadi tulang punggung perekonomian Indonesia. Berbeda dengan sektor lain yang sangat tergantung pada eksploitasi sumber daya alam, kekuatan ekonomi kreatif lebih bertumpu kepada keunggulan sumber daya manusia. Karya seni, arsitektur, buku, inovasi teknologi, dan animasi, berasal dari ide-ide kreatif pemikiran manusia ${ }^{16}$.

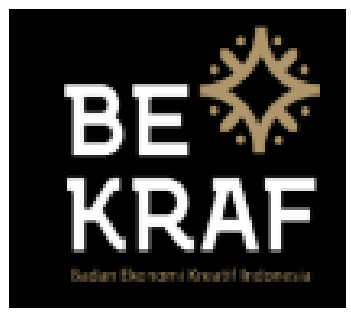

Gambar 4. Logo BEKRAF Indonesia

Sumber: http://data.bekraf.go.id/

\footnotetext{
${ }^{15} \mathrm{http} / / / \mathrm{www} \cdot k e m e n p e r i n . g o . i d / a r t i k e l / 4060 /$ Industri-Kreatif-Masih-Potensial

${ }^{16}$ http://www.bekraf.go.id/profil
} 
Bekraf mempunyai visi membangun Indonesia menjadi salah satu kekuatan ekonomi dunia dalam ekonomi kreatif pada 2030 nanti. Untuk mencapai visi tersebut, Bekraf merancang enam misi besar, yaitu:

1. Menyatukan seluruh aset dan potensi kreatif Indonesia untuk mencapai ekonomi kreatif yang mandiri.

2. Menciptakan iklim yang kondusif bagi pengembangan industri kreatif.

3. Mendorong inovasi di bidang kreatif yang memiliki nilai tambah dan daya saing di dunia internasional.

4. Membuka wawasan dan apresiasi masyarakat terhadap segala aspek yang berhubungan dengan ekonomi kreatif.

5. Membangun kesadaran dan apresiasi terhadap hak kekayaan intelektual, termasuk perlindungan hukum terhadap hak cipta.

6. Merancang dan melaksanakan strategi yang spesifik untuk menempatkan Indonesia dalam peta ekonomi kreatif dunia.

\section{METODE}

Metode penelitian yang digunakan adalah metode survey. Survey lapangan dilakukan dengan cara pengamatan disertai dengan pendokumentasian fenomena di sekitar tapak. Lokasi site berada di jalan sekunder, yaitu Jl. Kemang Raya yang memiliki batasan tapak pada bagian utara yaitu Jl. Kemang Raya, bagian barat dan selatan tapak berupa Jl. Taman Kemang 1, dan bagian timur tapak merupakan Kemang Square.

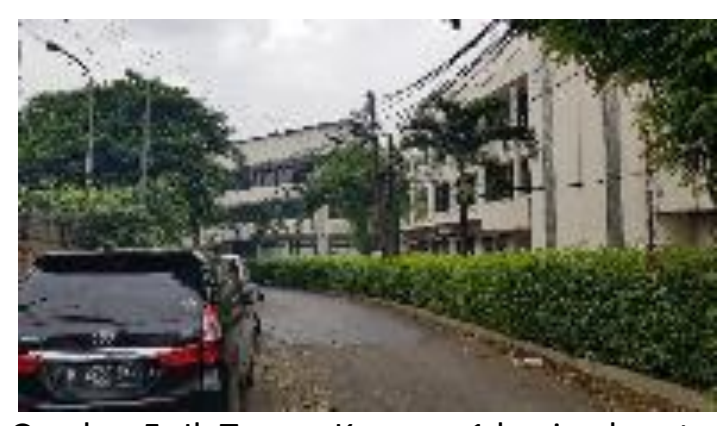

Gambar 5. Jl. Taman Kemang 1 bagian barat, Sumber: Penulis, 2019

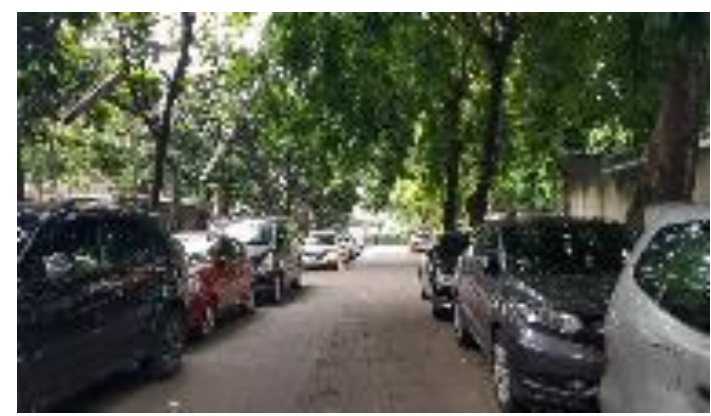

Gambar 7. Jl. Kemang Raya dan Pedestrian, Sumber: Penulis, 2019

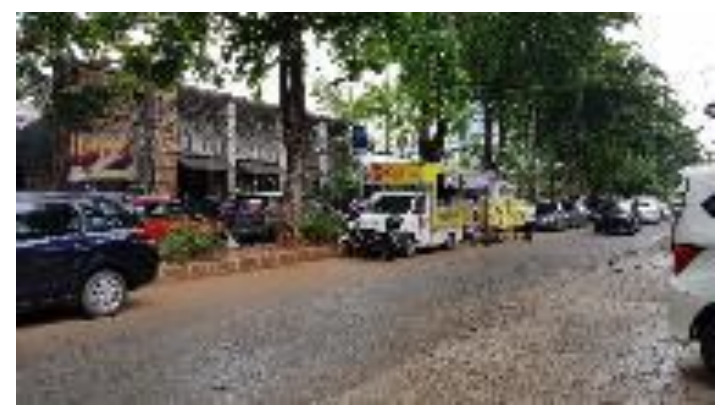

Gambar 6. Jl. Taman Kemang, Sumber: Penulis, 2019

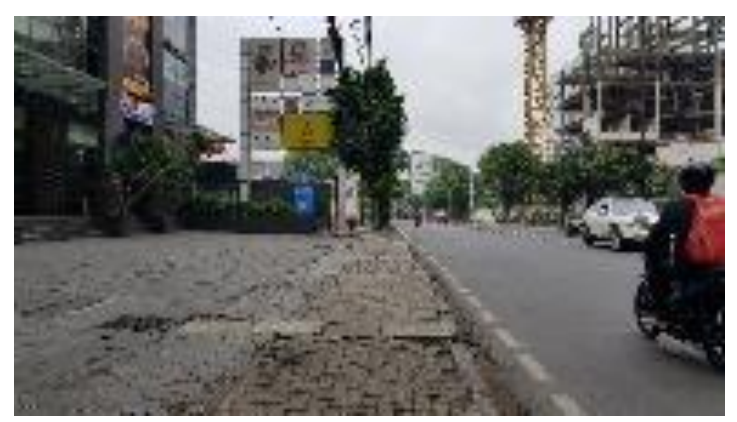

Gambar 8. Jl. Taman Kemang 1 bagian Selatan, Sumber: Penulis, 2019

Lingkungan di area tapak memiliki banyak pohon besar dan rindang. Lebar Jl. Taman Kemang 1adalah 6 meter, sedangkan lebar Jl. Kemang Raya adalah 10 meter yang dibagi dengan 2, dengan separator ditengahnya. Jl. Kemang Raya memiliki jalur pedestrian sebesar 2 meter. 


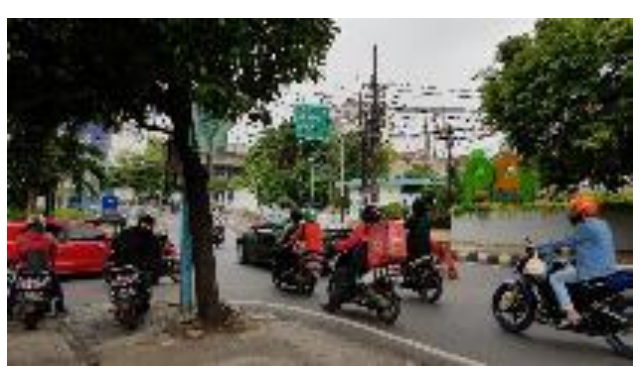

Gambar 9. Kondisi eksisting tapak 2, Sumber: Penulis, 2019

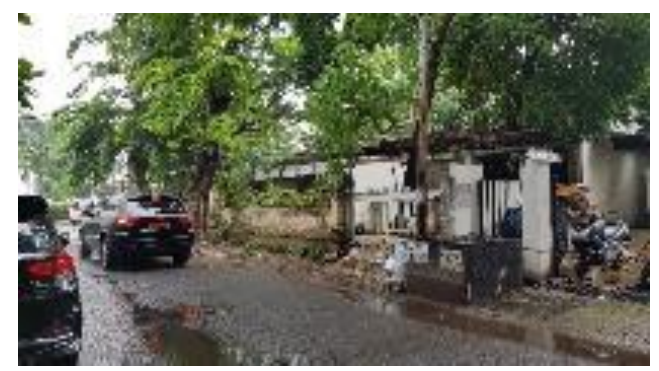

Gambar 11. Kondisi eksisting tapak 1, Sumber: Penulis, 2019

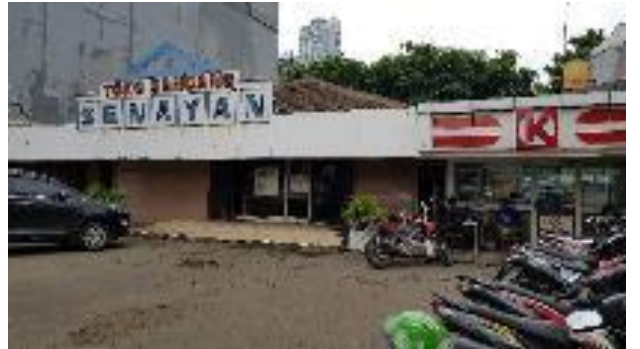

Gambar 10. Pertigaan Jl. Kemang Raya depan tapak, Sumber: Penulis, 2019

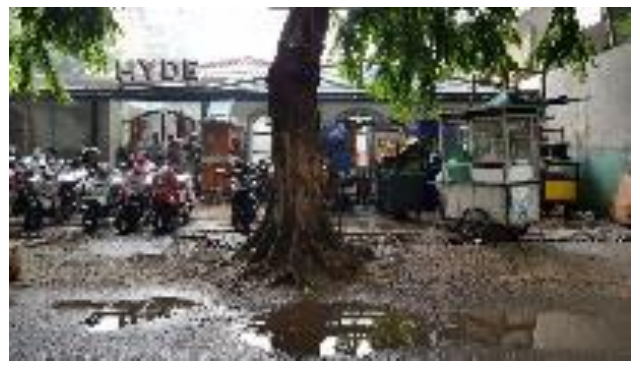

Gambar 12. Kondisi eksisting tapak 3, Sumber: Penulis, 2019

Kondisi eksisting tapak merupakan pertokoan tua yang sudah tidak berfungsi/ tutup. Pada area belakang tapak eksistingnya merupakan café yang sudah dirobohkan dan tidak digunakan, saat ini hanya digunakan untuk parkir motor untuk karyawan - karyawan yang bekerja dekat dengan café sekitar.rumah tua juga memiliki banyak tanaman liar dan pohon - pohon yang rindang. Hal tersebut bisa menjadi nilai lebih dari tapak yang diambil.

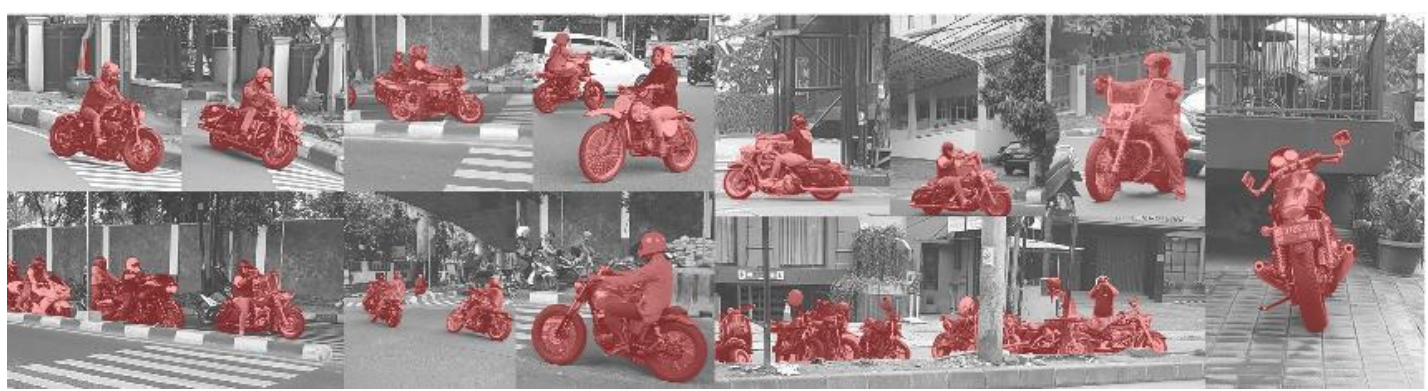

Gambar 13. Fenomena Motor Custom Sekitar Tapak, Sumber: Penulis, 2019

Survey lapangan juga dilakukan dengan cara pengamatan fenomena di sekitar tapak. Motor motor custom berlalu lalang seperti foto seperti gambar 13 yang diambil pada Jalan Pangeran Antasari dan Jalan Kemang Raya. Jalan Pangeran Antasari merupakan jalur Sunmori (Sunday Morning Ride) yang dilalui bikers ketika minggu pagi berkeliling Jakarta. Jalan Pangeran Antasari juga merupakan akses utama menuju tapak. 


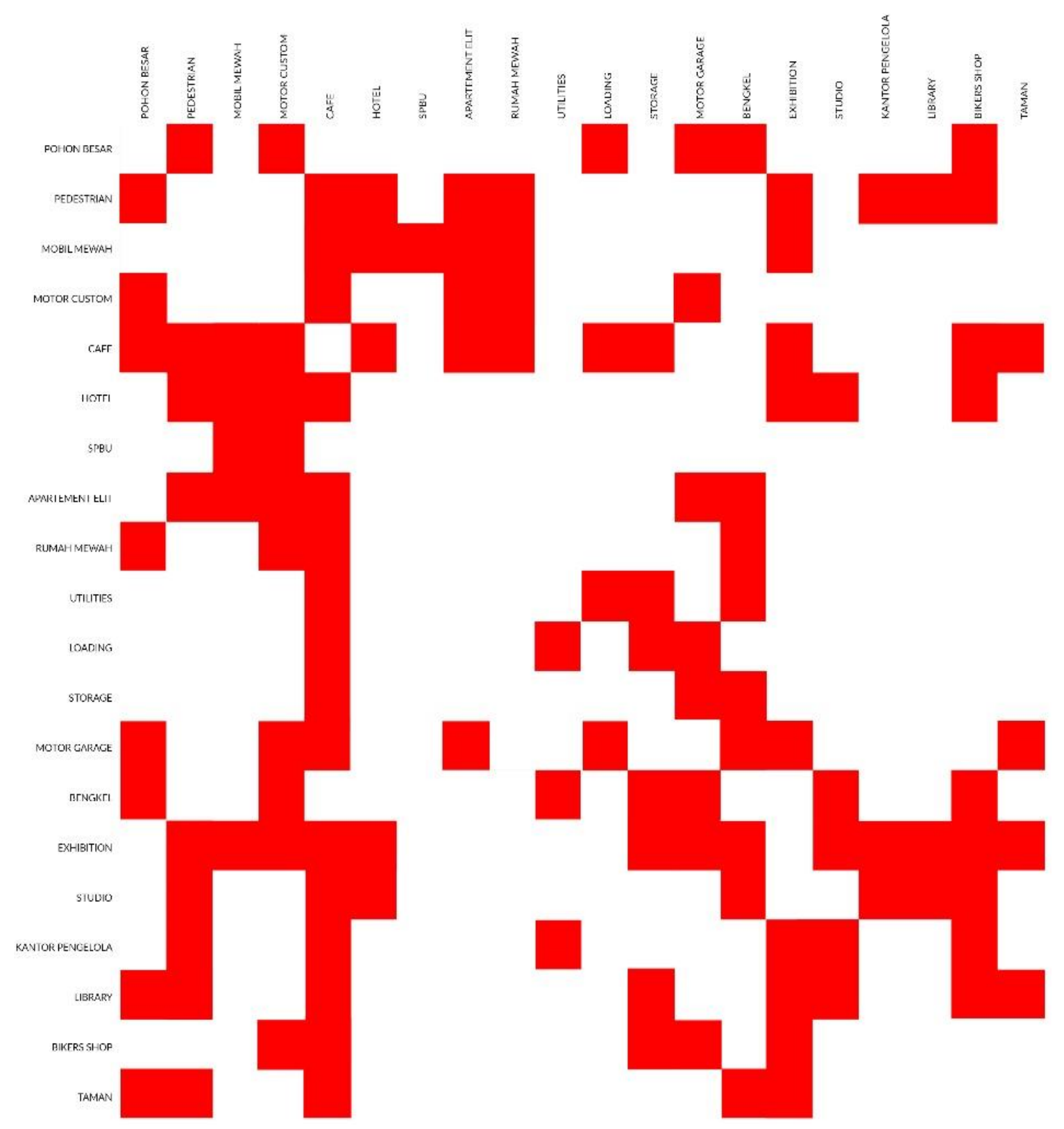

Gambar 14. Diagram Keterkaitan antara Program dengan Tapak, Sumber: Penulis, 2019

Fenomena tersebut direkam dikaitkan antara program dengan fenomena sekitar tapak. Polapola fenomena tersebut dituangkan ke dalam desain dengan metode Pattern Language. Pattern Language berawal dari kata language yang merupakan dasar ungkapan arsitektur sehingga kita harus mengetahui secara benar fungsi dan struktur pembentuk dari komunikasi ini. Language merupakan suatu susunan dari unsur-unsur yang memiliki pola-pola yang berbeda yang disusun dengan menggunakan suatu syarat tertentu namun memiliki kebebasan yang tak terbatas. Dengan begitu secara sederhana sebuah Bahasa bisa disimpulkan sebagai suatu komposisi yang dibentuk oleh rangkaian hal yang berbeda. Menurut Alexander Christoper, sebuah pattern language terdiri dari dua komposisi utama yang dirangkaikan sehingga bisa membentuk suatu Bahasa yang pada akhirnya terpolakan menjadi pesan yang ingin dikomunikasikan dari tempat tersebut yaitu pattern of events dan pattern of space, dua keadaan ini saling membentuk satu sama lain (Alexander,1979) sehingga keduanya menjadi kunci bagaimana suatu kualitas tanpa nama bisa terbentuk yang lalu dapat membentuk pola keruangan yang akan membentuk keterkaitan antar ruang. 


\section{DISKUSI DAN HASIL}

Dari data survey lapangan yang dilakukan dan data peraturan dari RDTR dapat dijadikan dalam acuan/patokan dalam mendesain gubahan massa.
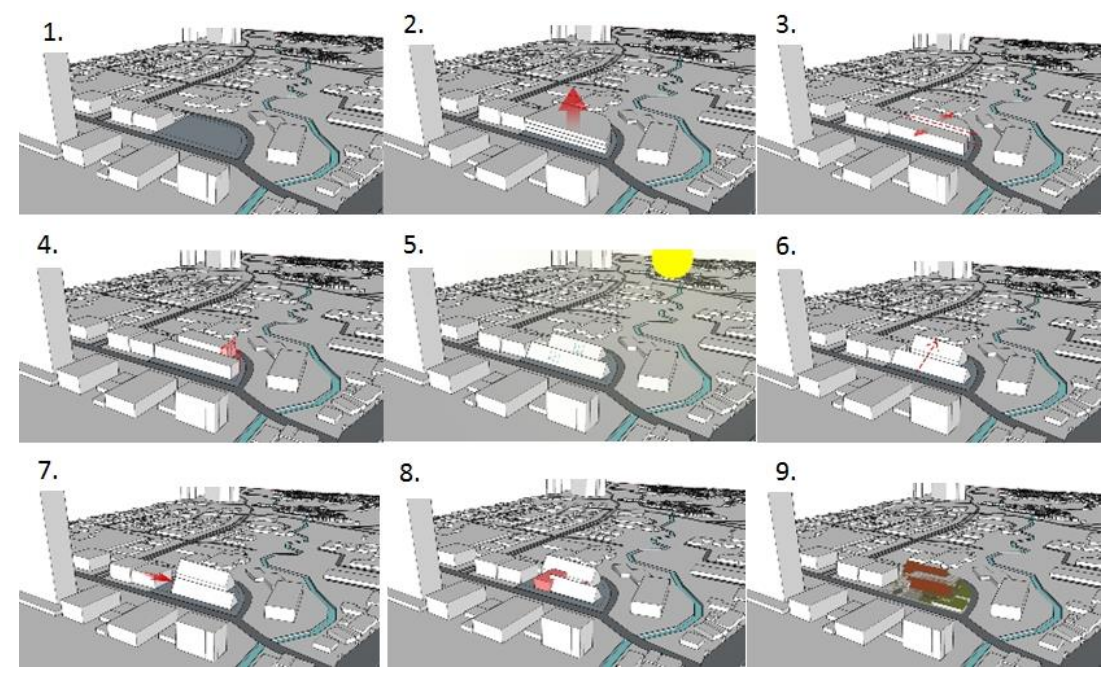

Gambar 15. Diagram Proses Gubahan Massa, Sumber: Pribadi, 2019

a. Tapak memiliki gsb bagian depan 6 meter, bagian tepi 5 meter, bagian belakan 6 meter. Massa bangunan di maksimalkan dengan dipotong dengan garis sepadan bangunan.

b. Massa bangunan ditinggikan sesuai dengan peraturan dari RDTR yakni 3 lantai.

c. Karakter tapak yang tebal membuat massa bangunan menjadi massive, massa bangunan dibelah dua agar memiliki pencahayaan dan pengudaraan yang lebih baik. Bidang massa bangunan menghadap ke bagian utara dan selatan dari tapak.

d. Massa bangunan bagian belakang dipendekan untuk mendefiniskan bentuk site yang lengkung untuk menjadi sebuah ruang.

e. Lokasi tapak yang berada di iklim tropis menjadikan massa memiliki bentuk segitiga untuk menciptakan bayangan dan mengalirkan curah air hujan yang tinggi.

f. Massa bangunan pertama (bagian depan) dibuat lebih rendah untuk mentransfer skala bangunan dan menciptakan hierarki antara jalanan ke dalam bangunan.

g. Massa pertama (bagian depan) digeser untuk membuat entrance masuk untuk pedestrian yang berasal dari pertigaan jalan kemang raya.

h. Kedua massa bangunan diberikan konektor untuk menciptakan organisasi ruang yang linear (loop). 


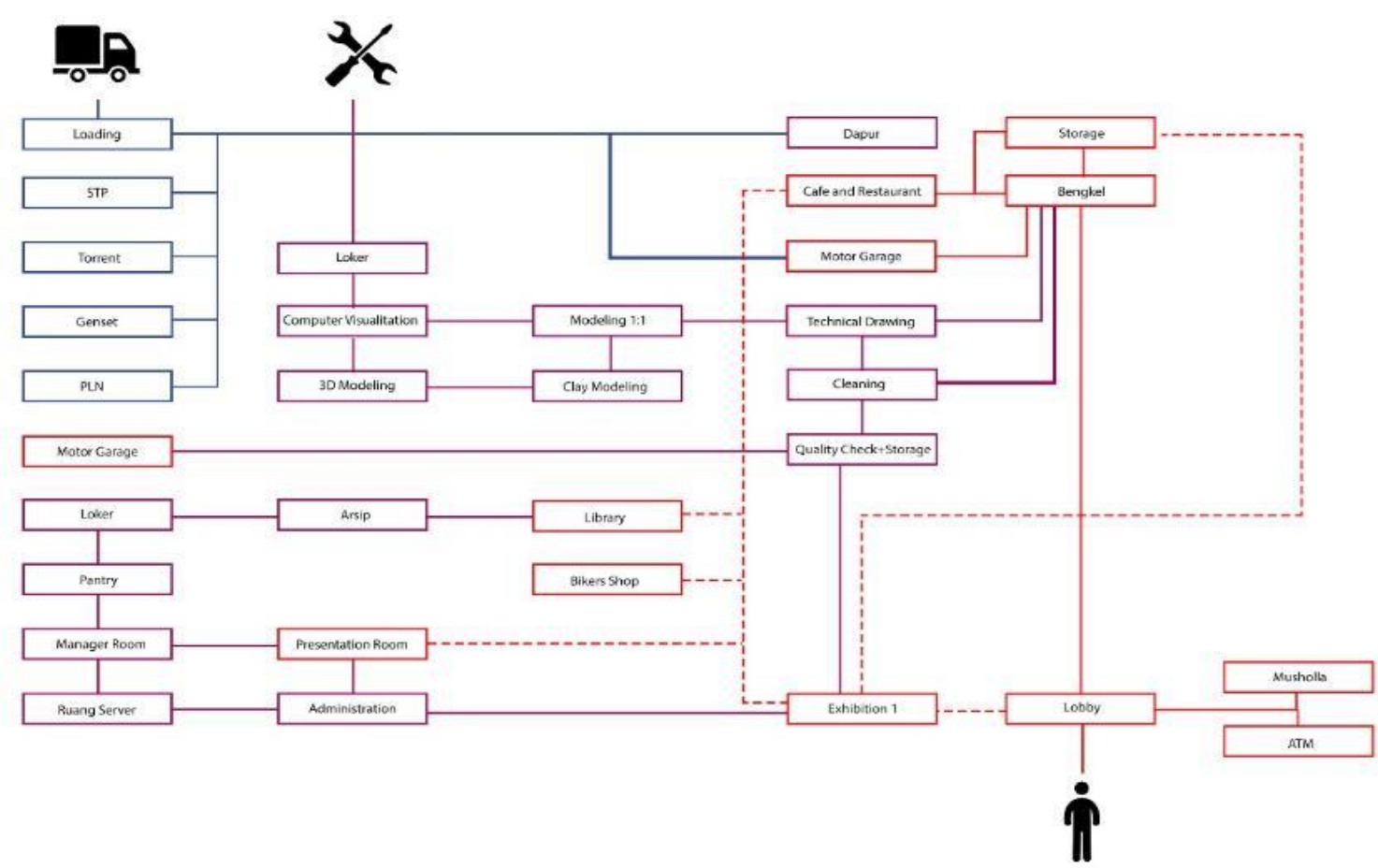

Gambar 16. Organisasi Ruang, Sumber: Penulis, 2019

Organisasi ruang merupakan hasil dari Pattern Language yang menjadikan pembentukan ruang ke ruang. Organisasi ruang dapat dipecah menurut aksesbilitasnya, akses dari pengunjung, akses untuk pengelola, dan akses untuk loading. Organisasi ruang juga berbicara mengenai runtutat perjalanan orang memasuki bangunan hingga keluar bangunan. Organisasi ruang tersebut dimasukan ke dalam gubahan massa dan tercipta ruang-ruang pada massa bangunan seperti pada gambar 17. 


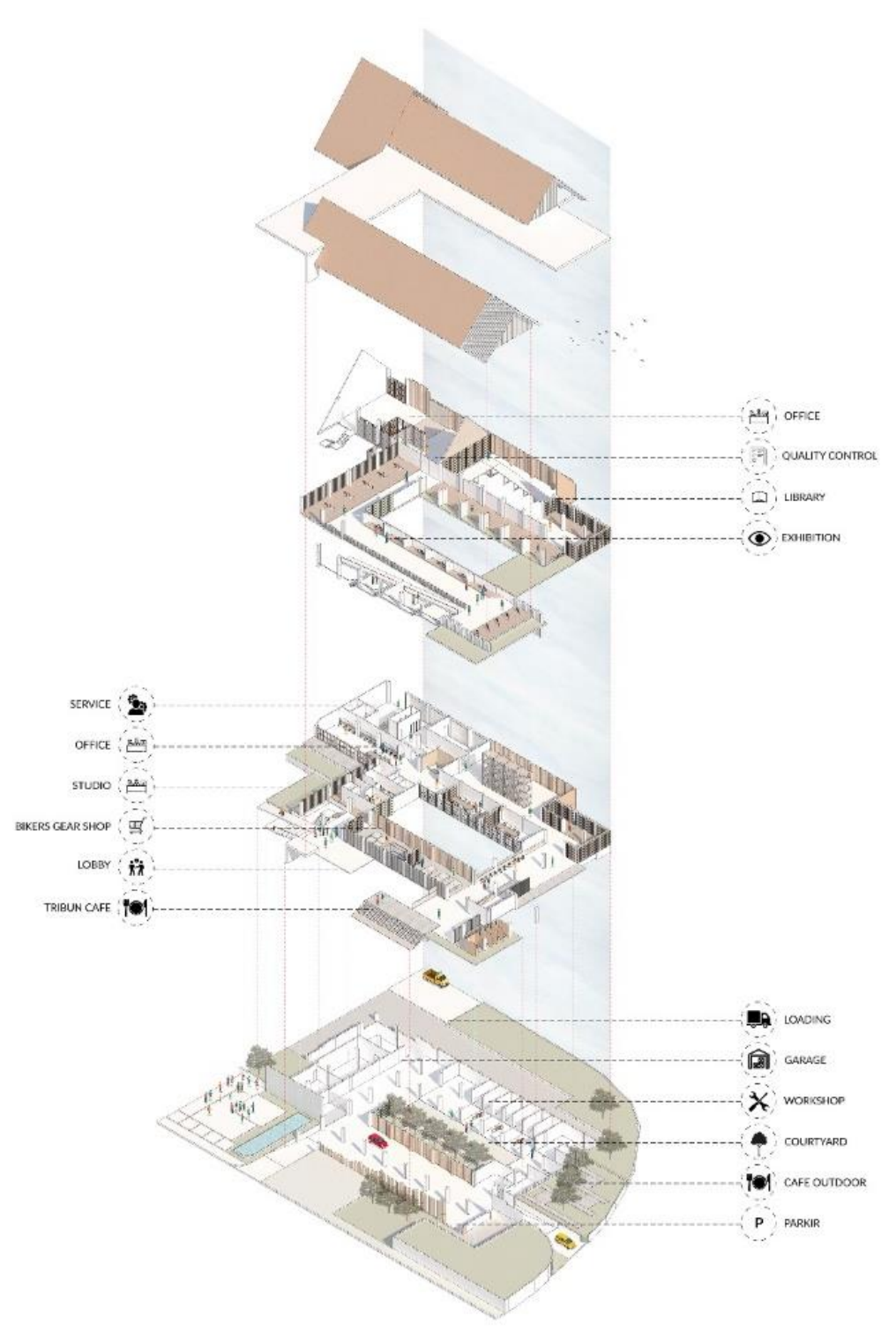

Gambar 17. Axono Explode, Sumber: Penulis, 2019

\section{KESIMPULAN DAN SARAN}

\section{Kesimpulan}

Kesimpulannya perubahan pola hidup milenial berpengaruh terhadap fungsi dari sebuah benda. Motor tidak lagi menjadi sebuah transportasi saja, melainkan menjadi sebuah tren/ gaya hidup. Ekonomi Kreatif menjadi penyokong ekonomi di Indonesia, industri kreatif yang didukung pemerintah memberikan signal positif untuk membuat Bengkel Motor Custom. Bengkel Motor Custom hadir untuk memajukan industri kreatif Indonesia, mampu memunculkan produk yang inovatif, serta dapat mengedukasi masyarakat luas tentang otomotif (motor custom), dan meningkatkan daya tarik akan produk lokal.

\section{Saran}

Adanya penambahan sub sektor lainnya di dalam program bangunan agar kolaborasi yang terjadi didalamnya semakin kaya. Menambah kapasitas modul bengkel untuk menjangkau lebih banyak Motor Custom. Meningkatkan kapasitas modul berarti meningkatkan kapasitas produksi, sehingga meningkatkan industri kreatif Indonesia. 


\section{REFERENSI}

Alexander, C. (1979). A Pattern Language. Towns Building Construction. California : Center for Environmental Structure

Badan Ekonomi Kreatif, sumber : www.bekraf.go.id/profil, diakses Februari 11, 2019

B.F. Skinner. ( 1938). The Behavior of Organisms: An Experimental Analysis.Cambridge, Massachusetts: B.F. Skinner Foundation.

Definisi Bengkel, sumber : http//bjmmotor.business.site/, diakses Januari 20, 2019

Definisi Bengkel, sumber : https://kbbi.web.id/bengkel, diakses Januari 20, 2019

Definisi Zaman, sumber : https://kbbi.kemdikbud.go.id/entri/zaman, diakses Januari 6, 2019

Generasi Milenial dan Era Industri, sumber : https: //news.detik.com/kolom/d3981811/genera similenial-dan-era-industri-40, diakses Desember 22, 2019

Generasi Millenial, UMKM, dan Media Pemasaran Digital, sumber : www.republika.co.id/ berita/ jurnalisme-warga/wacana/17/05/15/opziw5396-generasi Milenial-umkm-dan-mediapemasaran-digital, diakses Februari 10, 2019

Industri Kreatif Masih Potensial, sumber : www.kemenperin.go.id/artikel/4060/Industri-KreatifMasih-Potensial, diakses Januari 3, 2019

Kwick, R. (1974). Notoatmodjo, Soekidjo. (2003). Pendidikan Dan Perilaku Kesehatan, Rineka Cipta, Jakarta.

Majalah Otomotif: Dapurpacu, 2013

Maslow Hierarchy of needs, sumber : www.kompasiana.com/anantayoga/552a7b976ea8340c 0a552d02 /maslow-s-hierarchy-ofneeds, diakses Februari 2, 2019

Moneo, R. (1978). On Typology.

Notoatmodjo, S. (2003). Pendidikan Dan Perilaku Kesehatan. Rineka Cipta. Jakarta.

Soedarmo, H. (2008). Panduan Praktis Merawat dan Memperbaiki Sepeda Motor. Jakarta : Gramedia.

Tjahjono, G. (1999). Metode Perancangan Suatu Pengantar Untuk Arsitek dan Perancang. 